whale is 14 or 15 feet long at birth, is about 20 feet long and its whale-bone less than 2 feet long when it is weaned, but is not sexually mature until its length is about 50 feet and its whale-bone exceeds 10 feet.

2. As stated in my letter on the "Extermination of Whales" (Nature, Mar. 2) in the Greenland Sea in the period 1860-1909, only a small number were killed by the whalers, including those that may have died after breaking loose, two or three less than ten a year, and that notwithstanding this small mortality at the hands of their human enemies in these years they showed no signs of increase. It might be objected that the whalers were not the only enemies of the Greenland whale and that others came to an untimely end in other ways; but of this there is no evidence. In the Greenland Sea the Killer whale, its most likely enemy, is not found amongst the ice, and as far as I saw the whales do not appear to suffer or die from disease. Only those that died from harpoon wounds were found floating dead.

3. Harpoons were sometimes found in whales, which the animals appear to have carried about buried in them for a long time.

In the Greenland Sea, in 1863, my father killed a large whale in which he found an old harpoon marked 'Pow and Fawcus, Newcastle, 1839', and in 1872 he killed two others, also large, in each of which he found old harpoons (Buckland's " Log-book of a Fisherman ", etc., p. 247).

In Davis Strait in 1894 the Terra Nova killed a large whale (12 feet bone), in the blubber of which was found embedded a harpoon bearing the name 'Jean of Bo'ness', and dated forty years back. The Jeana well-known whaling ship-was lost in Davis Strait in 1857 (Zoologist, 1895, p. 94).

\section{Hartley Road,} Exmouth.

\section{Reduced Flowers of Ranunculus.}

I AM glad my letter to Nature (April 13, p. 568) has been the means of eliciting from Mr. MarsdenJones and Dr. Turrill a very interesting joint communication (NATURE, May 25, p. 798) on the above subject. I hope I have not unwittingly been attempting to steal their thunder !

The references to the literature they give are very welcome. Apparently these buttercup plants with reduced (female) flowers have hitherto failed to interest British field botanists - an instance perhaps of the lack of sympathetic feeling and co-operation between the systematists and the geneticists.

As yet I have not come across in this district the reduced form of Ranunculus bulbosus, but shall keep my eyes open now that the buttercup season is with us. Plants of $R$. acris with the small flowers and aborted stamens are appearing as usual.

If there be evolutionary significance in these reduced flowers, then seeing there are all grades between plants with completely hermaphrodite flowers and those with no functional stamens, it looks as if there is here an example in support of the view of "the inevitability of gradualness" (to adopt a famous phrase used in another connexion) in evolution.

The writers of the joint letter express surprise at my not mentioning a freak plant of Ranunculus acris I found here in the middle of a pasture field a few years ago. Reference to such a plant did not appear germane to the subject matter of my former letter, for I regard it as a sport which has no bearing on the evolutionary trend of the species. Others naturally may take a different view. It is pleasing, however, to know that it is of value to these workers on the genetics of the genus, especially as they have proved it to be functionally male only-a point which was not obvious to me at the time of its discovery. The original plant is still in the garden here. It does not grow nearly as strongly as the ordinary or reduced (female) form of Ranunculus acris; consequently in the wild state it might soon have failed to hold its own and been squeezed out of existence. It was a frail affair when I lifted it from the pasture. A feature of it not mentioned in the Marsden-Turrill letter is the distinctive character of its foliage. The leaves are somewhat crested and less sharply cut than those of the type, so that the plant can readily be recognised when not in flower.

Blaithwaite,

J. PARKIN.

Wigton, Cumberland, May 29.

\section{Nervous Impulse in Mimosa pudica.}

IN a letter under the above heading (NATURE, April 13, 1929) Prof. Hans Molisch describes certain experiments which appear to confirm the earlier work of Sir J. C. Bose. Space does not permit of a full discussion of these results, but it is rather surprising to find that Prof. Molisch regards the experiment of Bose on the supposed reflex arc as satisfactory evidence, since the fallacy in this experiment has already been demonstrated by $\mathrm{K}$. Umrath (Planta, 5, 1928, p. 295 , footnote).

As Umrath points out, and as I also have found, the serial reactions of the pinnæ take place in the same way, whether one stimulates a pinna of a leaf attached to a shoot or one from which the main pulvinus has been removed. This fact disposes of the contention that an afferent impulse is changed into an efferent one in the main pulvinus. Further, neither Sir J. C. Bose nor Prof. Molisch mentions the reactions of the secondary pulvini. I have noticed that if one stimulates one pinna, either electrically or by cutting, in the large majority of cases the secondary pulvini of the other pinnæ react before the main pulvinus, thus showing that the excitation has already reached them. As Umrath points out, there is a delay in the trans. mission between the secondary pulvinus and the basal pair of pinnules. This delay allows time for the excitation to reach the main pulvinus, which thus reacts before the excitation is apparent in the pinnules on the unstimulated secondary petioles.

Occasionally I have observed the excitation beginning to pass up the unstimulated pinnæ before the main pulvinus reacts, but usually the time which has elapsed is not sufficient for it to pass beyond the secondary pulvini.

It is therefore apparent the transition of the excitation from one pinna to another takes place at the apex of the petiole and not through a reflex arc passing through the main pulvinus.

\section{Ceylon University College,} Colombo, May 7.

\section{The Ratio of the Mass of the Proton to that of the Electron.}

IN a recent paper (Proc. Roy. Soc., 122, p. 358 ; 1929) Prof. A. S. Eddington reached the conclusion that the value of the physical constant $c h / 2 \pi e^{2}$ is given by the integer 136 . His theory reduces the evaluation of this constant essentially to the counting up of sym. metrical elements in a square array. The numbers

No. 3111, VoL. 123] 